\title{
SEISMIC PERFORMANCE EVALUATION OF PLASTERBOARD PARTITIONS VIA SHAKE TABLE TESTS
}

\author{
Gennaro Magliulo ${ }^{\mathrm{a} *}$, Crescenzo Petrone ${ }^{\mathrm{a}}$, Vittorio Capozzi ${ }^{\mathrm{a}}$, Giuseppe \\ Maddaloni $^{\mathrm{b}}$, Pauline Lopez ${ }^{\mathrm{c}}$, Gaetano Manfredi ${ }^{\mathrm{a}}$ \\ ${ }^{a}$ University of Naples Federico II, Department of Structures for Engineering and \\ Architecture, Naples, Italy \\ ${ }^{b}$ University of Naples Parthenope, Department of Technology, Naples, Italy \\ ${ }^{c}$ Siniat, Direction Innovation and $R \& D$, Avignon, France
}

\begin{abstract}
The damage of nonstructural components represents the largest contribution to the economic loss caused by an earthquake. Since nonstructural components are not amenable to traditional structural analysis, full-scale experimental testing is crucial to understand their behaviour under earthquake. For this reason, shaking table tests are performed to investigate the seismic behaviour of plasterboard partitions. A steel test frame is properly designed in order to simulate the seismic effects at a generic building storey. The tests are performed shaking the table simultaneously in both horizontal directions. To investigate a wide range of interstorey drift demand and seismic damage, the shakes are performed scaling the accelerograms at eleven different intensity levels.

The tested plasterboard partitions from Siniat exhibit a good seismic behaviour, both in their own plane and out of plane, showing limited damage up to $1.1 \%$ interstorey drift ratio. The correlation between the dynamic characteristics of the test setup and the recorded damage is evidenced. Finally, an interesting comparison between the experimental results and the analytical model is also performed.
\end{abstract}

\section{Keywords}

nonstructural components, dynamic identification, plasterboard partitions, seismic performance, shake table test, infilled frame

* Corresponding author: Gennaro Magliulo, University of Naples Federico II, Department of Structures for Engineering and Architecture (DIST), via Claudio, 21, I-80125 Naples, Italy; tel. +39 081768 3656, fax. +39 081768 5921; email: gmagliul@unina.it 


\section{Introduction}

In the last years, the scientific community research effort is moving towards the investigation of the seismic behaviour of nonstructural components. Nonstructural elements are those systems and components attached to the floors, roof and walls of a building or industrial facility that are not part of the main load-bearing structural system, but may also be subjected to large seismic actions (Villaverde 1997). The paper deals with plasterboard partition systems, certainly belonging to nonstructural components category.

The seismic performance of nonstructural elements is strongly inserted in the framework of the "Performance-based earthquake engineering" (Bertero and Bertero 2002). According to this approach, the global seismic performance is defined upon the behaviour of both structural and nonstructural elements. Nonstructural components behaviour is critical especially for strategic buildings (De Stefano et al. 2012), that must be operative immediately after an earthquake, also considering that these components usually exhibit damage even for lowintensity earthquakes.

Studies available in bibliography (Taghavi and Miranda 2003) point out that the damage of the nonstructural components gives the largest contribution to the economic loss due to an earthquake. The economic impact is much more severe if losses of inventory and downtime cost are considered: the cost related to nonstructural components failure may easily exceed the replacement cost of the building (EERI 1984). Moreover, the failure of nonstructural components may also represent a threat to life safety. A partition or infill overturning may easily result in injuries or casualties.

Few studies were conducted in the past on nonstructural components performance evaluation. This research group has already performed analyses on this topic but referring suspended ceiling systems (Magliulo et al. 2012a). Concerning plasterboard partitions some experimental tests were carried out in order to investigate their seismic behaviour (Adham et al. 1990; Anderson 1981; Landolfo et al. 2006; Restrepo and Lang 2011; Retamales et al. 2011). A series of experimental tests are conducted by Lee et al. (2007): in order to characterize the seismic performance of drywall partitions typically used in Japanese buildings, to observe the entity of the damage under cyclic loading conditions and to quantify the corresponding repair costs, four full-scale drywall partitions sheathed with two layers of gypsum boards on both faces are constructed and tested. A full-scale shake table test on a specimen, consisting of both gypsum board partition walls and suspended ceiling systems, is carried out by McCormick et al. (2008). The test shows the main damages which occur at different drift levels and provides preliminary data for a test on a full-scale steel moment frame. An innovative set up for non-structural component testing is proposed by Mosqueda et al. (2009): a modular two-level shake platform is used in order to evaluate the behaviour of both displacement and acceleration-sensitive nonstructural components. Gypsum wall and piping systems are also tested to evaluate their seismic performance. Through the experimental results, reported in Filiatrault et al. (2010), the authors conduct a seismic fragility analysis of partition walls and propose innovative construction details in order to minimize the seismic damage. On the basis of tests experimental results, as those just described, several researchers (Fulop and Dubina 2004a; Fulop and Dubina 2004b; Kanvinde and Deierlein 2006; Restrepo 
and Bersofsky 2011) propose numerical and analytical model representative of the seismic behaviour of these nonstructural components.

In this paper the seismic performance of innovative plasterboard partitions is investigated. Such partitions are designed in order to not interfere with the hosting structure up to moderate level of interstorey drifts $(\sim 0.5 \%)$. The seismic performance evaluation is pursued via shake table tests with increasing intensity. The shake table tests, combined with the definition of a proper test frame in which the partitions are housed, allow investigating the seismic behaviour of the systems subjecting them simultaneously to interstorey drifts in their own plane and accelerations in the out of plane direction.

The recorded damage states are correlated to an engineering demand parameter; some considerations on the hysteretic curve are made through a complete analysis of the recorded quantities. Finally a model of the test setup is introduced comparing the experimental results with the analytical ones.

\section{Experimental facilities, test setup, specimen and input}

The shake table tests, performed in order to investigate the seismic behaviour of plasterboard internal partitions, are carried out at the laboratory of the Department of Structures for Engineering and Architecture of the University of Naples Federico II.

The tests are performed by the earthquake simulator system, consisting of two $3 \mathrm{~m}$ x $3 \mathrm{~m}$ square shake tables. Each table is characterized by two degrees of freedom in the two horizontal directions. The maximum payload of each shake table is 200 $\mathrm{kN}$ with a frequency range of $0-50 \mathrm{~Hz}$, acceleration peak equal to $1 \mathrm{~g}$ at the maximum payload, velocity peak equal $1 \mathrm{~m} / \mathrm{sec}$ and total displacement equal to $500 \mathrm{~mm}( \pm 250 \mathrm{~mm})$. Only one shake table is used in this experimental testing program (Fig. 1a).

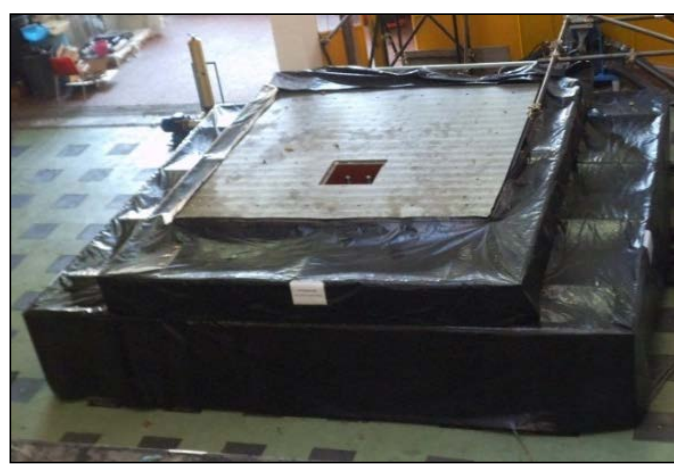

(a)

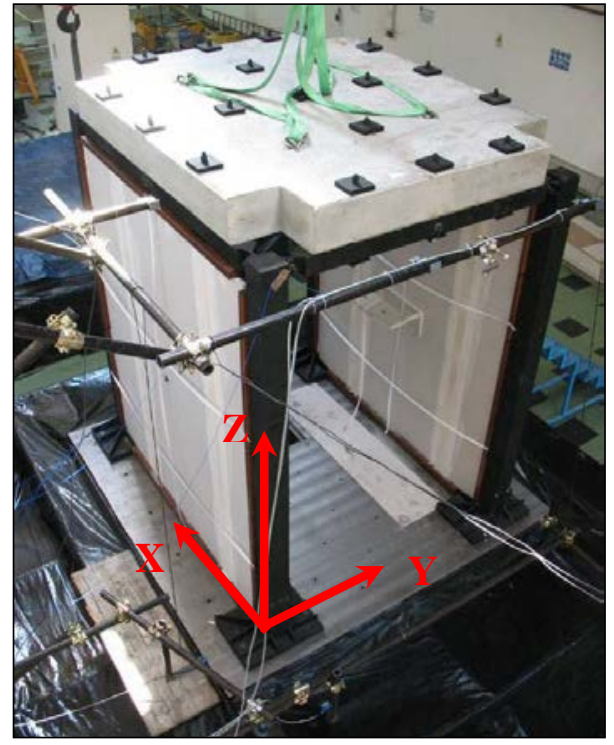

(b)

Fig. 1 (a) Earthquake simulator system used in the tests; (b) general (XYZ) view of the test setup

A general view of test setup is shown in Fig. 1b, while a schematic representation of the tested specimen is presented in Fig. 2. The main components of the tested partitions are: the "base and lateral runners", U-steel section profiles screwed 
respectively to base floor and columns, with dimension 40-75-40 mm and 6/10 mm thick; the "top runner", an U-steel section profile screwed to top floor, with dimension 80-75-80 mm and 10/10 mm thick; "vertical studs", U-section profiles housed in the upper and lower runners, but not screwed to them, with dimension 47-74-50 mm, 6/10 mm thick, spaced $600 \mathrm{~mm}$; the outer layer of "PREGYPLAC BA13" plasterboards, gypsum panels properly sized and horizontally jointed and weighing $90 \mathrm{~N} / \mathrm{m}^{2}$; the inner layer of "PREGY LaDURA BA13" plasterboards, with high surface and mechanical resistance conferred by the presence of wooden fibres within the gypsum, properly positioned in order to prevent low resistance sections and weighing $128 \mathrm{~N} / \mathrm{m}^{2}$. Each layer is $12.5 \mathrm{~mm}$ thick and provides thinned edges. The plasterboards are screwed only on vertical studs through phosphated and drilling screws spaced $30 \mathrm{~cm}$. Joints between boards of the external layer (PREGY LaDURA BA13) are sealed by the joint compound. The gap between the plasterboards and the perimeter is filled with acrylic silicone.

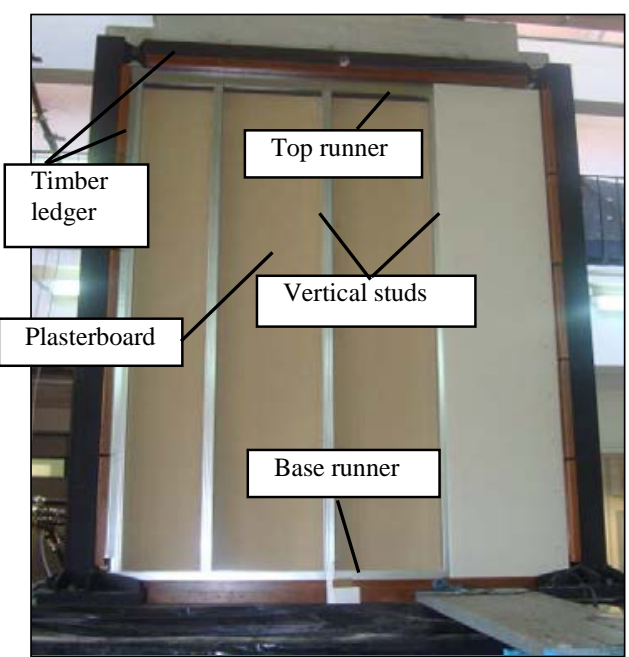

(a)

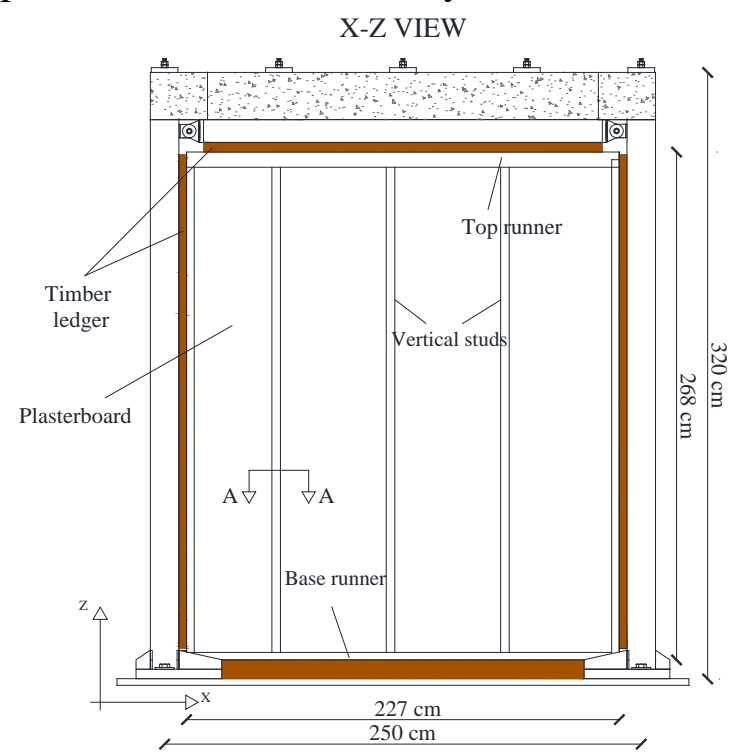

(b)

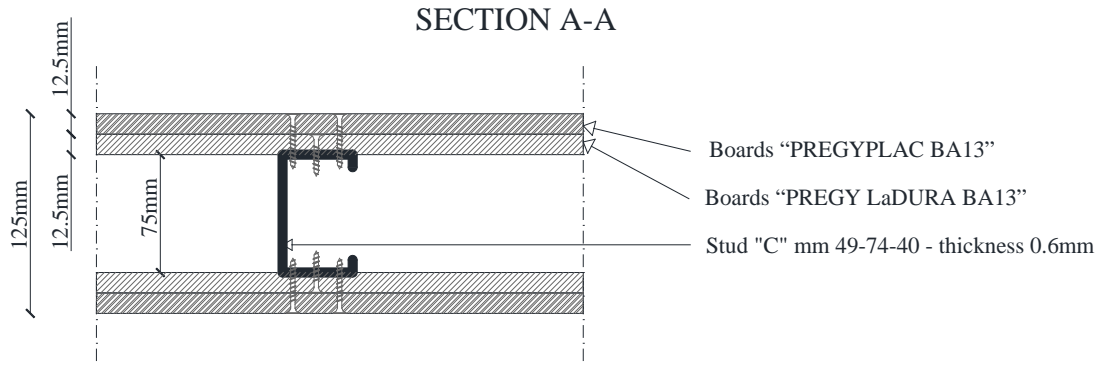

(c)

Fig. 2 Internal plasterboard partition: (a) overview; (b) graphical scheme; (c) horizontal cross section

\section{Test frame: idea, design and parametric study}

A steel test frame is properly designed and built (Fig. 3) with the purpose of simulating the seismic effects on the partitions. The test frame is designed so as to simulate the behaviour of a generic story of a building, in which the partitions are installed. The geometry of the test frame is defined taking into account three requirements: (i) realistic value of mass; (ii) realistic interstorey height $h$, assumed equal to $2.74 \mathrm{~m}$; (iii) realistic interstorey displacement $d_{r}$, assumed equal to $0.005 h$ for a Damage Limit State earthquake with 50 year return period. 

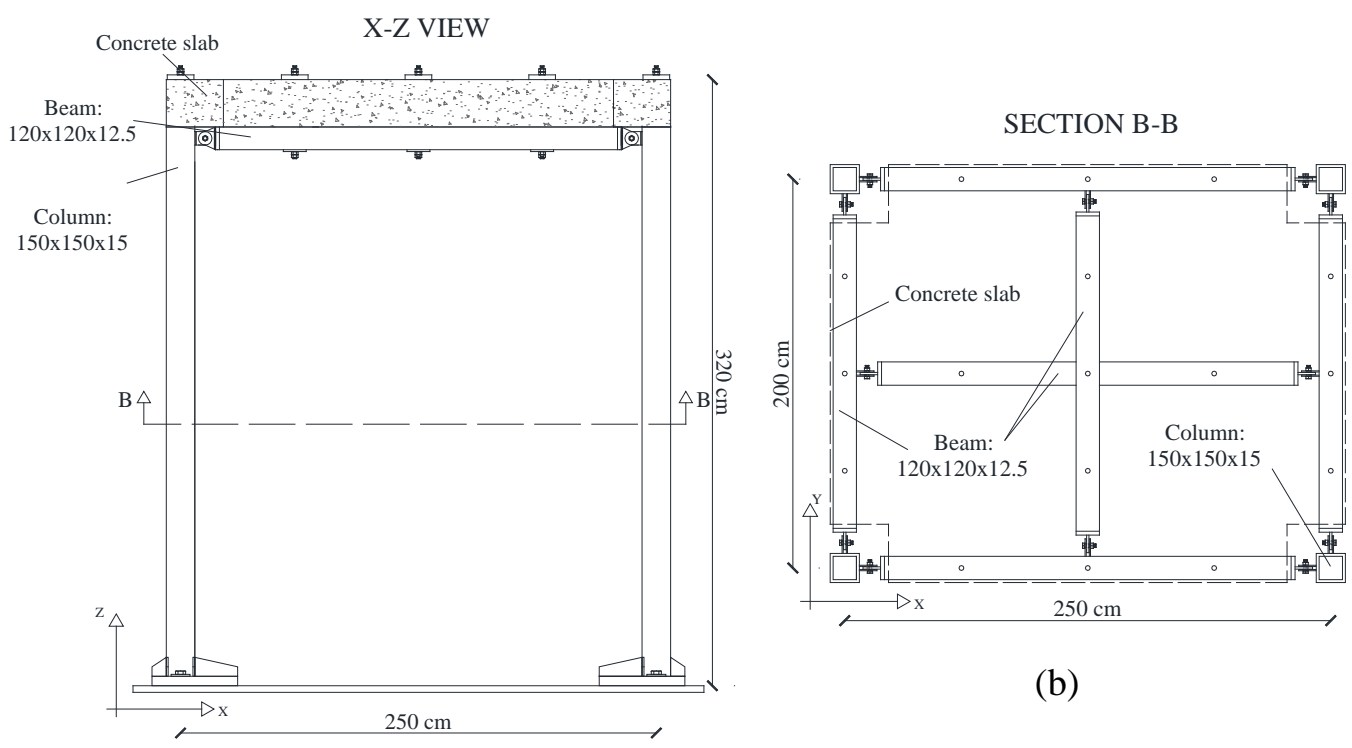

(a)

Fig. 3 Scheme of test setup: (a) lateral view, (b) horizontal cross section

In order to select the cross section dimensions of the columns of the test frame a parametric study is conducted to satisfy the before mentioned strict requirements. Firstly, a cantilever scheme is adopted, capable to reach the same displacement of a frame scheme with rigid beams, inducing a halved moment at the base of the columns with respect to the frame one. Hollow squared cross sections are chosen in order to guarantee the same lateral behaviour in the two orthogonal directions. A high grade steel C45 is chosen for the columns, considering the high level of stress expected during the shakings.

The parametric study is prudently conducted assuming that the steel test frame does not interact with the partitions in sustaining the horizontal loads. The assumed quantities are:

- the maximum spectral ordinate $\mathrm{S}_{\mathrm{a} \text {,max }}$, equal to $2.40 \mathrm{~g}$ and obtained from the most intense seismic input at the shake table;

- the maximum spectral ordinate $S_{a, D L S}$, equal to $0.96 \mathrm{~g}$ corresponding to a Damage Limit State earthquake with 50-year return period;

- the maximum lateral displacement $\Delta$, evaluated as $\Delta=S_{a \text {, max }} / S_{a, D L S} \cdot 0.005 \cdot h=3.43 \mathrm{~cm}$, considering that the test frame is designed to remain in the elastic range for all the shakings.

A set of steel hollow square cross sections are considered. For each of them, the following quantities can be evaluated (Fig. 4), using simple relationships:

- the equivalent mass of a SDOF system $E M R=4 \cdot \frac{\Delta}{h^{3}} \cdot \frac{3 \cdot E I}{S_{a, \max }}$, required to reach the target displacement $\Delta$, where I is the moment of inertia of the considered cross section and $\mathrm{E}$ is the Young modulus;

- the maximum stress $(M S)$ in the cross section at the base, resulting from the linear dynamic analysis with the most intense seismic input.

Considering that the floor area is equal to $5 \mathrm{~m}^{2}$ and in order to achieve the above mentioned requirements, the mass is limited to be in the range $4.0 \mathrm{t} \div 6.0 \mathrm{t}$. Obviously, to prevent the yielding of the steel columns, the maximum stress is limited to be less than the yielding stress, i.e. $430 \mathrm{MPa}$. These two limitations lead 
to the choice of a steel profile with $150 \mathrm{~mm}$ x $150 \mathrm{~mm} \times 15 \mathrm{~mm}$ cross section, as highlighted in red in Fig. 4, where the parametric study is summarized.

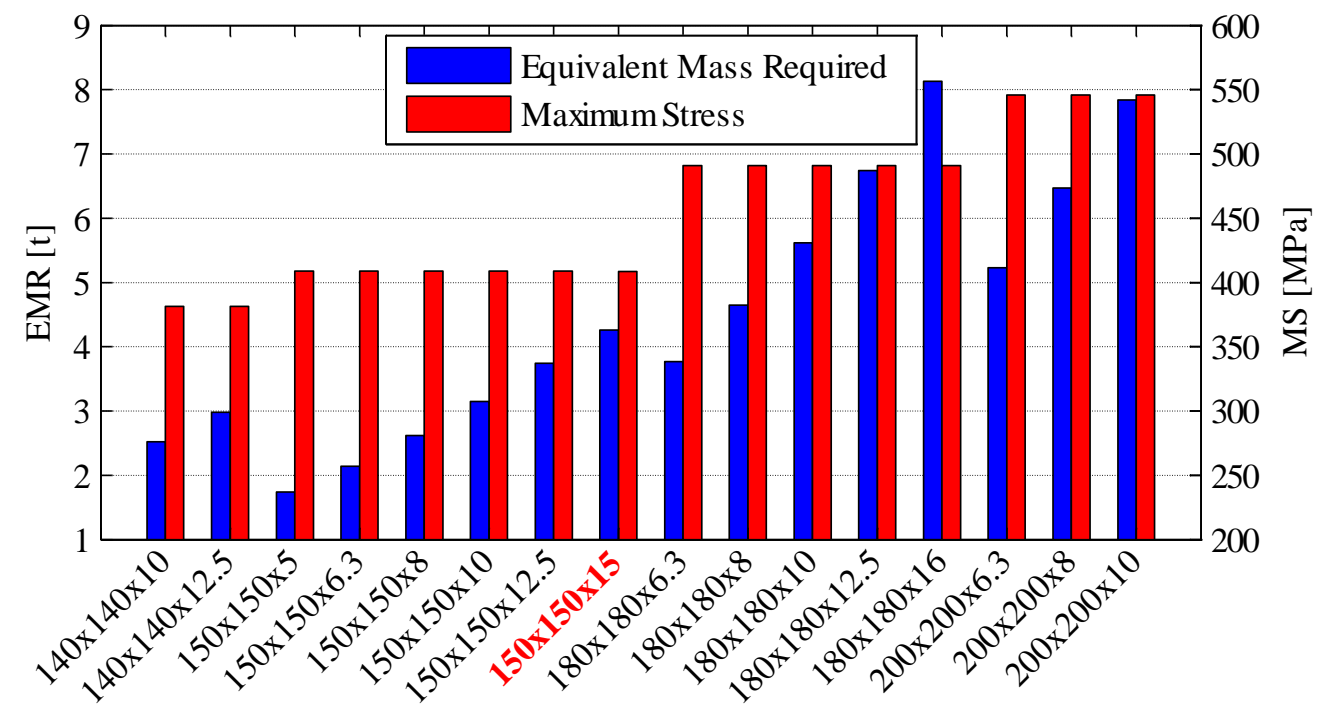

Fig. 4 Parametric study for the definition of the column cross sections: Equivalent Mass Required (EMR) and the Maximum Stress (MS) for each considered column cross section

The final result is a $2.50 \mathrm{~m}$ (X direction) $\times 2.00 \mathrm{~m}$ (Y direction) $\times 2.89 \mathrm{~m}(\mathrm{Z}$ direction) inverted pendulum test fixture. The test frame is composed of welded square hollow columns (150 mm x $150 \mathrm{~mm}$ x $15 \mathrm{~mm}$ ) of C45 steel material and rolled square hollow beams (120 mm x $120 \mathrm{~mm} \times 12.5 \mathrm{~mm})$ of steel S275; the beam-column connections are bolted. A horizontal frame made of rolled square hollow steel profiles $(120 \mathrm{~mm} \times 120 \mathrm{~mm} \times 12.5 \mathrm{~mm})$ is bolted to the principal beams of the test frame, as shown in Fig. 3. A reinforced concrete slab with class $\mathrm{C} 45 / 55$ concrete is placed on the roof of the structure. Its plan dimensions are 2.15 $\mathrm{m} \times 2.65 \mathrm{~m}$ with thickness equal to $0.25 \mathrm{~m}$ suitably shaped to allow relative beamcolumn rotations. The concrete slab is connected to the test frame with prestressed bolts, in order to guarantee enough friction strength at the steel beams-to-slab interface for the transfer of inertia forces.

A FEM model of the test frame is assembled by means of the computer program SAP2000 (Computers and Structures 2010). Each element of the test frame is implemented as elastic "beam" finite element. The FEM model is implemented in order to perform the design analysis and to obtain an estimation of the first period along both the orthogonal directions of the test frame. The two first translational periods are equal to $0.24 \mathrm{~s}(4.17 \mathrm{~Hz})$. The test frame is designed according to Eurocode 3 (CEN 2005a; CEN 2005b) and 8 (CEN 2004b) provisions by dynamic linear elastic analysis. The total seismic weight of the test frame is equal to 42.5 $\mathrm{kN}$.

\section{Test setup and specimen: mounting detailed description}

Two partitions are contemporary tested in order to maintain symmetry in the seismic behaviour of test frame. The specimen is a plain drywall partition with dimensions of $2.68 \mathrm{~m}$ (height) by $2.27 \mathrm{~m}$ (width) with $12.5 \mathrm{~cm}$ thickness (Fig. 2). It is installed between two columns, in particular along the longest side $(2.50 \mathrm{~m})$ of test fixture, connected by the perimeter U-section runners to a timber ledger covering the steel elements. Between the plasterboards and the wooden supports, a $0.8 \mathrm{~cm}$ to $1 \mathrm{~cm}$ gap is left. 
The installation procedure of the partition wall is as follows:

a) Base, lateral and top runners are sequentially screwed to top and bottom beams and to columns (Fig. 5a and b).

b) Vertical studs are simply housed in the top and base runners; they are not attached to the runners through the use of screws (Fig. 5c).

c) The first (inner) layer (PREGY LaDURA BA13) of gypsum plasterboards is only attached to vertical studs by screws with $30 \mathrm{~cm}$ step on each face of drywall partition; there is no screw that connects plasterboard to runners. This configuration allows the vertical studs to slide with respect to the lateral runner avoiding any collaboration between the partition and structure.

d) The second (outer) layer (PREGYPLAC BA13) of gypsum boards is attached to the first one by screws on each face of the drywall partition. The installation is made in order to prevent the formation of low resistance sections. Therefore, they are arranged so that joints are staggered (Fig. 5d).

e) Joints between boards of the second layer are sealed by joint compound.

f) The gap between the plasterboards and the perimeter is filled with acrylic silicone.

The above presented construction technology allows the partition to rigidly move within the bay in which it is installed without absorbing significant forces (neglecting the contribution of the silicone). In case the structure exhibits relative displacements larger than the separation gap, the partition can rigidly move within the bay up to relative displacement at least equal to twice the separation gap width. Hence, a $8 \mathrm{~mm}$ wide gap allows the partition to not absorb significant force at least up to $16 \mathrm{~mm}$ relative displacement, i.e. 0.5\% interstorey drift ratio.

The partitions are designed for the out-of-plane seismic force evaluated according to Eurocode 8 prescriptions on nonstructural components. The out-of-plane seismic demand on the nonstructural component is evaluated assuming a $0.3 \mathrm{~g}$ peak ground acceleration and that the component is installed at the last storey of a building. The resistance of the partition is evaluated according to Eurocode 3 (CEN 2004a), neglecting the contribution of the boards to the out-of-plane strength of the partition. 


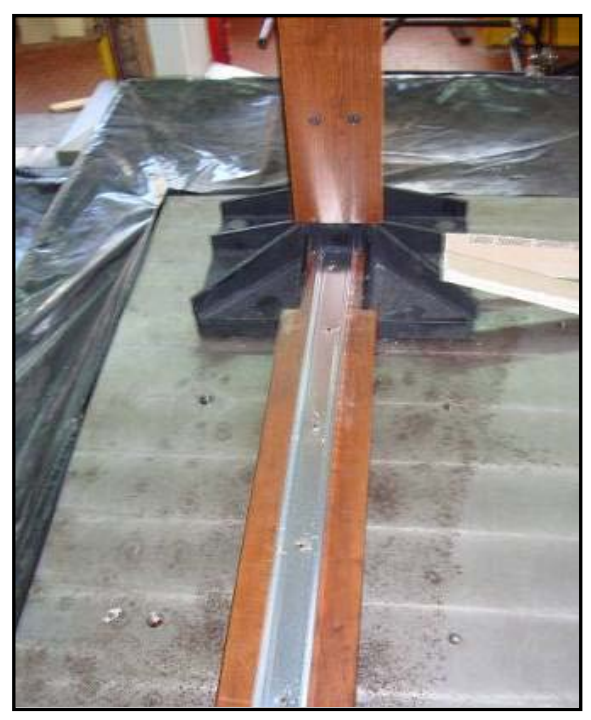

(a)

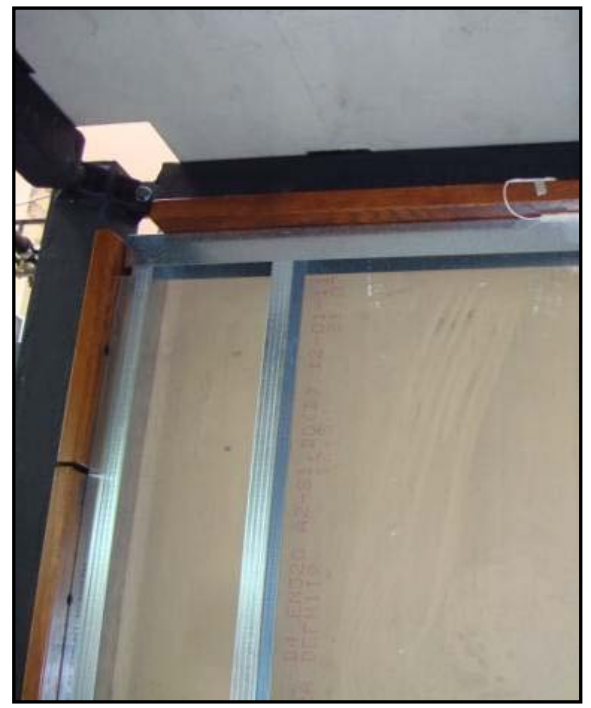

(c)

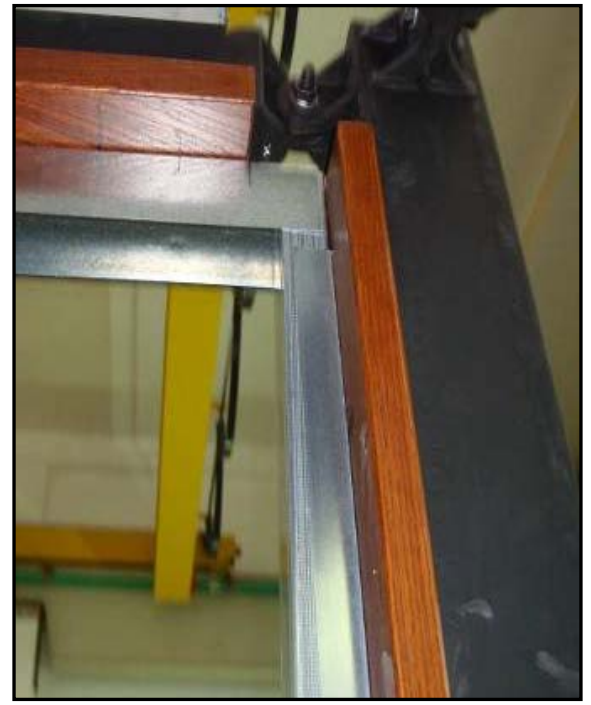

(b)

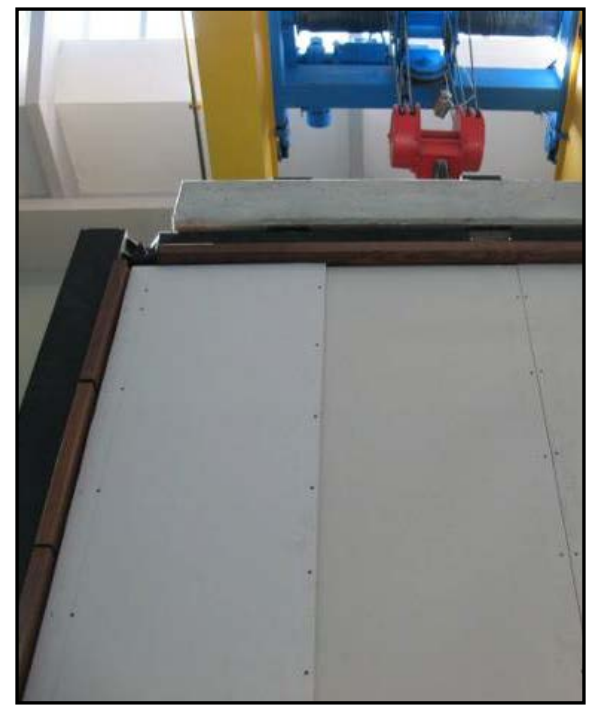

(d)

Fig. 5 Installation procedure: (a) base runner; (b) top and lateral runners; (c) vertical studs; (d) plasterboard second (outer) layer

\section{Instrumentation}

Accelerometers, strain gauges and laser-optical sensors are used to monitor the response of the test frame and partitions (Fig. 6).

In order to control roof rigid rotation and its displacements adequately, two triaxial accelerometers (named TRI-103762, TRI-103765) are installed at the centre of the principal beams in $\mathrm{X}$ and $\mathrm{Y}$ directions (Fig. 6b). Other two accelerometers (named TRI-103763, TRI-103766) are also arranged in two different points of the test frame: one accelerometer is placed at the centre of the partition (TRI-103763) and the other one at the column base (TRI-103766).

Eight strain gauges are adopted and indicated in Fig. 6a: four strain gauges are placed on the vertical steel studs (SG-m1) and perimeter runners (SG-s1, SG-i1, SG-i2), two at the column base (SG-i3, SG-i4) and two on the plasterboard (SGm2, SG-i5).

Six laser-optical sensors are used to monitor displacements of specific points of the test frame. Three of the six lasers are placed at steel base plate mid-height (base plate that connects column to shake table); the remaining three sensors 
monitor concrete slab displacement. In Fig. 6b the exact sensors arrangement is presented.

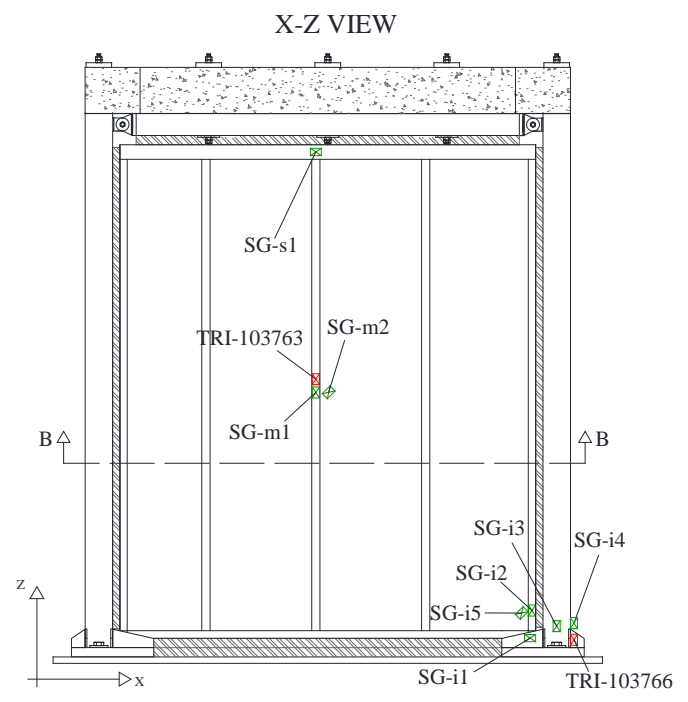

(a)

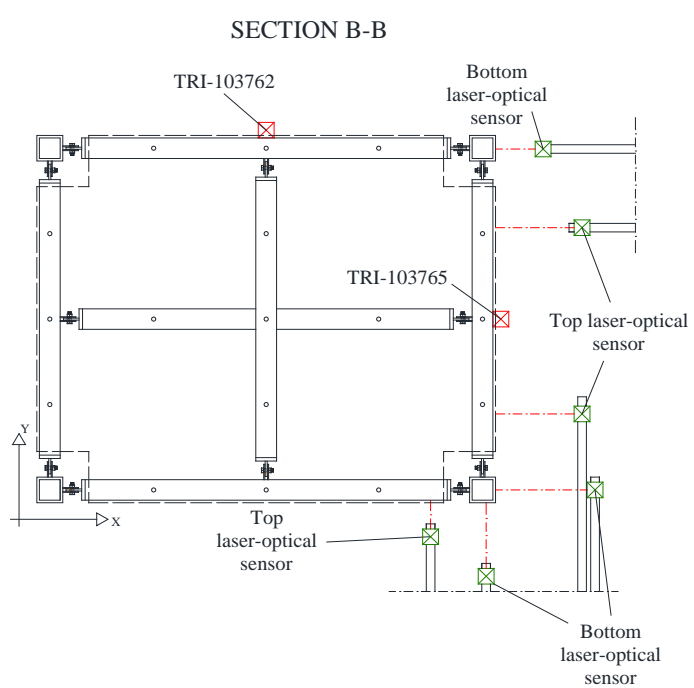

(b)

Fig. 6 Scheme of test instrumentation: (a) lateral view; (b) horizontal cross section

\section{Input and testing protocol}

The table input is provided through acceleration time histories representative of expected/target ground motion and acting simultaneously along the two horizontal directions; the time histories are artificially defined in order to match the Required Response Spectrum (RRS), provided by the ICBO-AC156 code "Acceptance criteria for seismic qualification testing of nonstructural components" (ICBO 2000).

According to ICBO (ICBO 2000), the RRS is obtained as a function of the spectral acceleration at 0.2 seconds, $S_{\mathrm{DS}}$, which is the parameter characterizing the ground motion. For horizontal design-basis earthquake shaking, the International Building Code (ICC 2000) defines the design spectral response acceleration at short periods $\mathrm{S}_{\mathrm{DS}}$ as:

$$
S_{D S}=\frac{2}{3} \cdot F_{A} \cdot S_{S}
$$

where $F_{A}$ is a site soil coefficient, set equal to 1 in this study, and $S_{S}$ is the mapped Maximum Considered Earthquake (MCE) spectral acceleration at short periods.

The selection procedure is performed for a RRS corresponding to $\mathrm{S}_{\mathrm{Ds}}$ equal to $1.50 \mathrm{~g}$; the records (in $\mathrm{X}$ and $\mathrm{Y}$ direction) are then scaled in order to match other levels of the target spectrum.

The earthquake histories used to test the partitions are generated according AC156 code procedure. In details, a baseline signal is defined starting from nonstationary broadband random excitations with energy content from 1.3 to $33.3 \mathrm{~Hz}$ and onesixth-octave bandwidth resolution. The selected baseline earthquake has a total length equal to 30 seconds and presents a rise time, a steady state and a decline time of the resultant acceleration record. Then, the signal is enhanced by introducing wavelets using the spectrum-matching procedure of RSP Match program (Hancock et al. 2006) in order to make it compatible with RSS. The matching procedure is ensured over the frequency range from 1.3 to $33.3 \mathrm{~Hz}$; the elastic response spectrum ordinates shall not be lower than 0.9 times RRS and 
larger than 1.3 times RRS (according to EC8 (CEN 2004b) and AC156 (ICBO 2000) rules, respectively). In order to obtain a drive motion compatible with the shaking table acceleration, velocity and displacement limits, the so obtained matched record is band passed filtered over the same range frequency. Two different time histories are defined for the two horizontal directions.

Fig. 7 shows the obtained time histories for the $\mathrm{X}$ (blue line) and $\mathrm{Y}$ (red line) directions in terms of acceleration, velocity and displacement, their elastic response acceleration spectra, the RRS corresponding to $S_{D s}$ equal to $0.30 \mathrm{~g}$ and the RRS scaled to $90 \%$ and $130 \%$.

Additional information on the test input is present in Magliulo and Manfredi (2011).
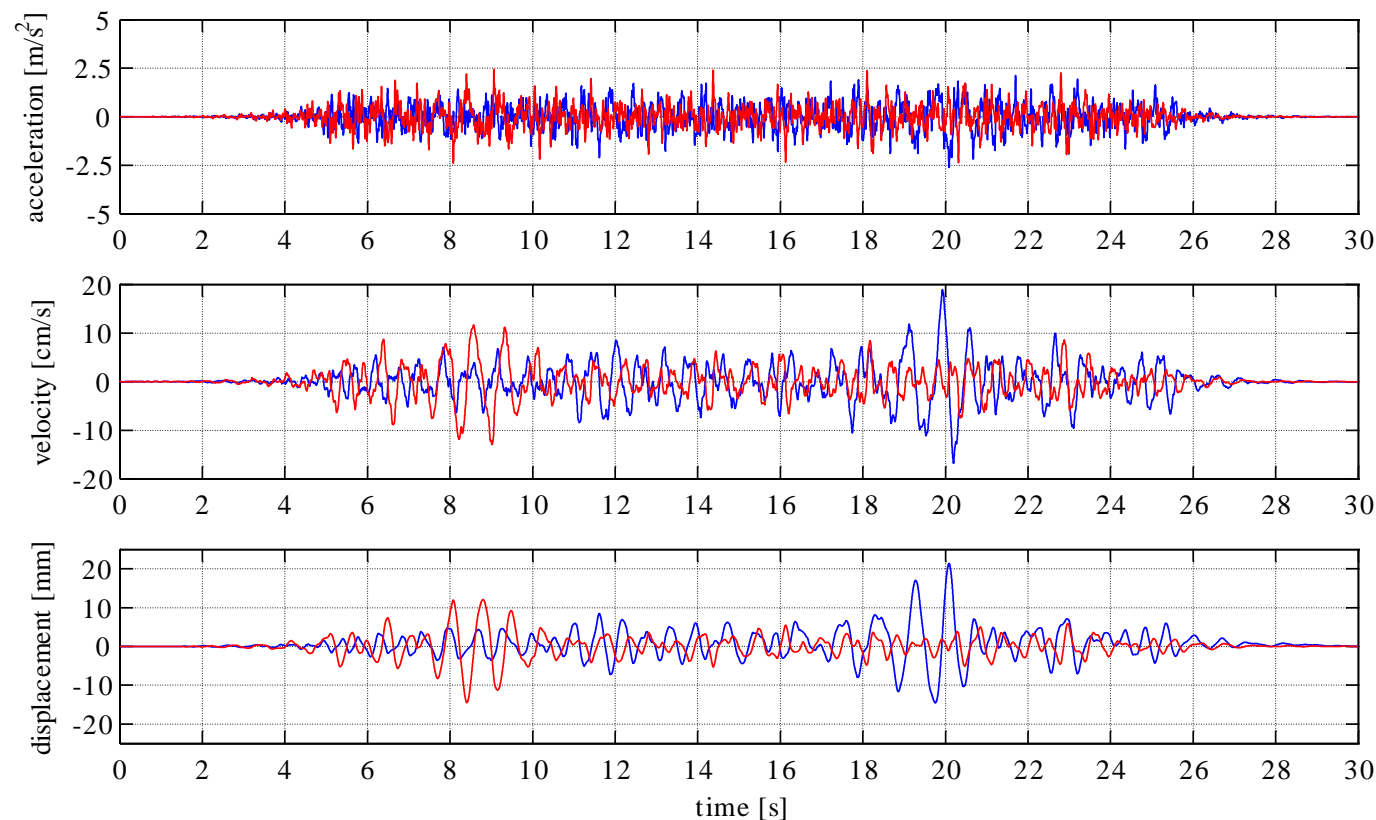

(a)

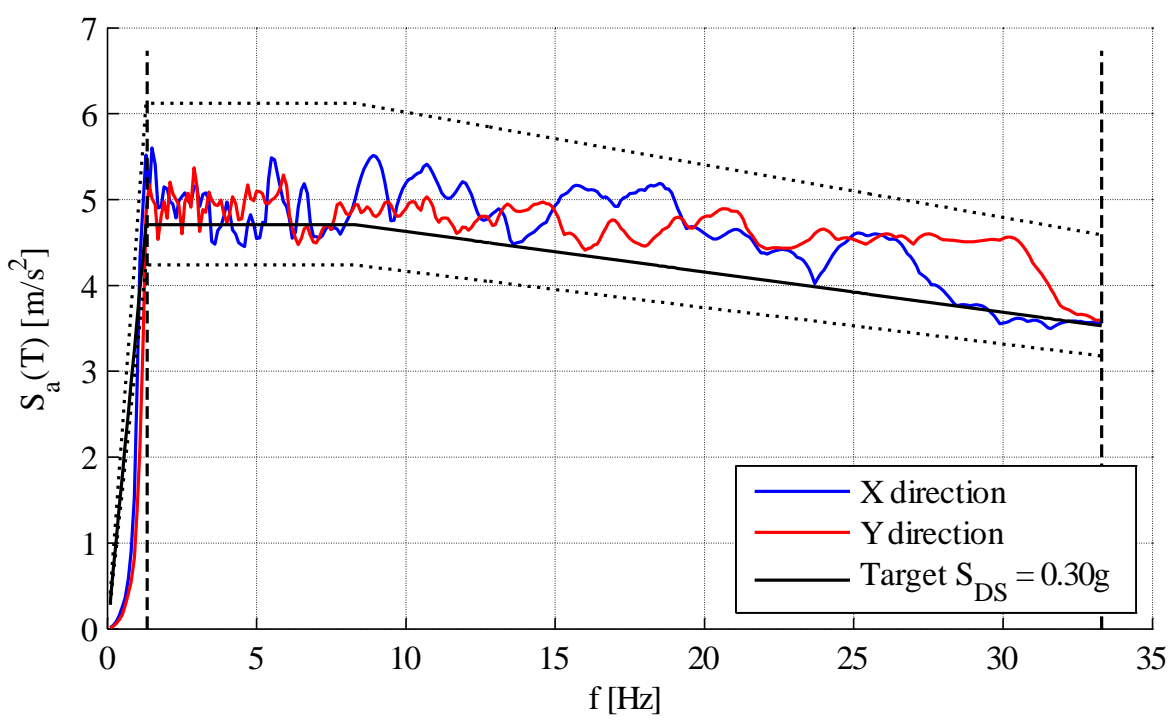

(b)

Fig. 7 Input time histories and spectra for $S_{D S}$ equal to 0.30 g: (a) acceleration, velocity and displacement time-history - X direction (blue) and Y direction (red); (b) input accelerogram spectra, RRS (bold line), upper and lower limits (dashed line), matching frequency range (vertical dashed line) 
The input levels range are chosen from $S_{D S}=0.10 \mathrm{~g}$ to $S_{D S}=1.50 \mathrm{~g}$ in order to generalize the execution of the test, being representative of a large range of real earthquakes. Such acceleration range implies that the partition is subjected to interstorey drifts larger than the limit, i.e. 0.5\%, required by Eurocode for standard partitions and infill. Indeed, the test frame is designed in order to exhibit a $0.5 \%$ interstorey drift for an earthquake characterized by $S_{\mathrm{DS}}$ equal to $0.60 \mathrm{~g}$, representative of an earthquake with $a_{g}=S_{D S} / 2.5=0.24 \mathrm{~g}$, i.e. an intensity level of earthquake with 50 years return period in a high seismicity zone according to the Paulay and Priestley (1992) indications.

In particular, 8 bidirectional (B) and 3 unidirectional (U) tests, with different intensity values, are chosen, as shown in the Table 1.

Table 1 Test ID, typology and $S_{D S}$ values for the different input test levels

\begin{tabular}{cccccccccccc}
\hline Test ID & 1 & 2 & 3 & 4 & 5 & 6 & 7 & 8 & 9 & 10 & 11 \\
\hline Test typology & $\mathrm{B}$ & $\mathrm{B}$ & $\mathrm{B}$ & $\mathrm{B}$ & $\mathrm{B}$ & $\mathrm{B}$ & $\mathrm{B}$ & $\mathrm{B}$ & $\mathrm{U}$ & $\mathrm{U}$ & $\mathrm{U}$ \\
\hline$S_{D S}[\mathrm{~g}]$ & 0.10 & 0.15 & 0.22 & 0.30 & 0.45 & 0.60 & 0.90 & 1.05 & 1.20 & 1.35 & 1.50 \\
\hline
\end{tabular}

Even if AC156 (ICBO 2000) is implicitly intended for acceleration-sensitive components, such as ceilings, the input motion is defined according to such a procedure for the following reasons:

- internal partitions are mainly displacement sensitive components; however, out of plane acceleration can cause the damage/collapse of such components;

- the use of a flexible test frame, subjected to the defined input motions, allows investigating the behaviour of the tested component at different levels of relative displacement demands.

\section{Test results and observations}

\section{Dynamic identification}

Standard methods for the dynamic identification of the test setup, both bare and infilled, are used in order to evaluate the influence of the plasterboard partitions on the steel test frame. Obviously, the procedures are applied only in the longitudinal direction of the partition. The procedures are described in details in Chopra (2001).

The results of the dynamic identification procedures are summarized in the Table 2.

Table 2 Outcomes of the dynamic identification procedures performed on bare and infilled frame in terms of natural frequency $f_{n}$ and damping ratio $\xi$ (Magliulo et al. 2012b)

\begin{tabular}{|c|c|c|c|c|c|}
\hline \multirow{2}{*}{$\begin{array}{l}\text { Method } \\
\text { Structure }\end{array}$} & \multicolumn{2}{|c|}{ Transmissibility curve } & \multicolumn{2}{|c|}{ Transfer curve } & \multirow{2}{*}{$\begin{array}{c}\text { Free } \\
\text { vibration } \\
\text { decay } \\
\zeta[\%]\end{array}$} \\
\hline & $f_{n}[\mathrm{~Hz}]$ & $\zeta[\%]$ & $f_{n}[\mathrm{~Hz}]$ & $\zeta[\%]$ & \\
\hline Bare frame & 3.81 & $0.94 \%$ & 3.86 & $1.55 \%$ & $0.65 \%$ \\
\hline Infilled frame & 4.02 & $8.33 \%$ & - & - & - \\
\hline
\end{tabular}

Considering these results, it can be concluded that:

- The natural frequency matches the analytical one, mentioned in the previous Section: the assumed restraints and constraints well model the behaviour of the bare test frame. 
- The innovative plasterboard partitions do not significantly influence the natural frequency of the test frame. The goal of not interfering with the hosting structure is achieved.

- The damping ratio of the test setup significantly increases with the insertion of the partition within the test frame, causing a beneficial effect in the dynamic response.

\section{Results summary}

Using the selected drive motions, eight bidirectional and three unidirectional shaking tests along $X$ direction (see Fig. 1b) are performed. In Table 3 the maximum recorded values of acceleration at the base and on the roof of the test frame are listed; the maximum accelerations on the partition, both in plane (i.p.) and out of plane (o.o.p.), are then compared to those values. As visible, due to dynamic amplification, the maximum value of acceleration recorded at the base of the table is completely different from the ones recorded on the roof and on the partitions. This aspect may be crucial for experimental tests on shaking table. For this reason, the procedure described in Maddaloni et al. (2011), concerning the optimization of the drive motion to predict the signal recorded at desired locations, i.e. on the partitions, using a compensation procedure, will be taken into account in the next experimental testing program.

It should be noted that during test no. 9, 10 and 11 some problems have occurred in acquiring accelerograms data.

Table 3 Maximum recorded accelerations at the test frame base and roof in $\mathrm{X}$ and $\mathrm{Y}$ directions and at the partition centre both in plane (i.p.) and out of plane (o.o.p.) for the different test intensities

\begin{tabular}{ccccccccc}
\hline Position & \multicolumn{2}{c}{ Base } & \multicolumn{2}{c}{ Roof } & \multicolumn{2}{c}{ Partition } \\
\hline Accelerometer & \multicolumn{2}{c}{ Table } & \multicolumn{2}{c}{103762} & \multicolumn{2}{c}{103765} & \multicolumn{2}{c}{103763} \\
\hline Direction & $X$ & $Y$ & $X$ & $Y$ & $X$ & $Y$ & i.p. & o.o.p. \\
\hline test no. 1 & $0.10 \mathrm{~g}$ & $0.17 \mathrm{~g}$ & $0.09 \mathrm{~g}$ & $0.20 \mathrm{~g}$ & $0.08 \mathrm{~g}$ & $0.19 \mathrm{~g}$ & $0.08 \mathrm{~g}$ & $0.26 \mathrm{~g}$ \\
\hline test no. 2 & $0.13 \mathrm{~g}$ & $0.22 \mathrm{~g}$ & $0.13 \mathrm{~g}$ & $0.32 \mathrm{~g}$ & $0.13 \mathrm{~g}$ & $0.31 \mathrm{~g}$ & $0.13 \mathrm{~g}$ & $0.38 \mathrm{~g}$ \\
\hline test no. 3 & $0.19 \mathrm{~g}$ & $0.27 \mathrm{~g}$ & $0.19 \mathrm{~g}$ & $0.43 \mathrm{~g}$ & $0.19 \mathrm{~g}$ & $0.42 \mathrm{~g}$ & $0.19 \mathrm{~g}$ & $0.45 \mathrm{~g}$ \\
\hline test no. 4 & $0.23 \mathrm{~g}$ & $0.35 \mathrm{~g}$ & $0.27 \mathrm{~g}$ & $0.54 \mathrm{~g}$ & $0.26 \mathrm{~g}$ & $0.56 \mathrm{~g}$ & $0.24 \mathrm{~g}$ & $0.54 \mathrm{~g}$ \\
\hline test no. 5 & $0.35 \mathrm{~g}$ & $0.47 \mathrm{~g}$ & $0.47 \mathrm{~g}$ & $0.76 \mathrm{~g}$ & $0.50 \mathrm{~g}$ & $0.80 \mathrm{~g}$ & $0.35 \mathrm{~g}$ & $0.73 \mathrm{~g}$ \\
\hline test no. 6 & $0.50 \mathrm{~g}$ & $0.57 \mathrm{~g}$ & $0.81 \mathrm{~g}$ & $0.97 \mathrm{~g}$ & $0.82 \mathrm{~g}$ & $0.97 \mathrm{~g}$ & $0.46 \mathrm{~g}$ & $0.95 \mathrm{~g}$ \\
\hline test no. 7 & $0.81 \mathrm{~g}$ & $0.90 \mathrm{~g}$ & $1.66 \mathrm{~g}$ & $1.32 \mathrm{~g}$ & $1.69 \mathrm{~g}$ & $1.32 \mathrm{~g}$ & $1.30 \mathrm{~g}$ & $1.34 \mathrm{~g}$ \\
\hline test no. 8 & $0.95 \mathrm{~g}$ & $1.03 \mathrm{~g}$ & $2.22 \mathrm{~g}$ & $1.54 \mathrm{~g}$ & $2.20 \mathrm{~g}$ & $1.53 \mathrm{~g}$ & $1.82 \mathrm{~g}$ & $1.81 \mathrm{~g}$ \\
\hline test no. 9 & $1.12 \mathrm{~g}$ & - & N/A & - & N/A & - & N/A & N/A \\
\hline test no. 10 & $1.43 \mathrm{~g}$ & - & $3.84 \mathrm{~g}$ & - & N/A & - & N/A & N/A \\
\hline test no. 11 & $1.85 \mathrm{~g}$ & - & $4.14 \mathrm{~g}$ & - & N/A & - & N/A & N/A \\
\hline
\end{tabular}

Relative displacements are also evaluated using the laser sensors records. In Table 4 the maximum recorded relative displacements in $\mathrm{X}$ and $\mathrm{Y}$ directions are listed and the maximum interstorey drifts are evaluated. Values up to $1.08 \%$ drift are recorded, representative of a moderate earthquake intensity level. 
Table 4 Maximum recorded relative displacements and interstorey drifts in X and Y directions for the different test intensities

\begin{tabular}{ccccc}
\hline & \multicolumn{2}{c}{ Relative displacement } & \multicolumn{2}{c}{ Interstorey drift } \\
\hline Direction & $X$ & $Y$ & $X$ & $Y$ \\
\hline test no. 1 & $0.9 \mathrm{~mm}$ & $3.2 \mathrm{~mm}$ & $0.03 \%$ & $0.12 \%$ \\
\hline test no. 2 & $1.1 \mathrm{~mm}$ & $5.3 \mathrm{~mm}$ & $0.04 \%$ & $0.19 \%$ \\
\hline test no. 3 & $1.3 \mathrm{~mm}$ & $8.1 \mathrm{~mm}$ & $0.05 \%$ & $0.29 \%$ \\
\hline test no. 4 & $2.4 \mathrm{~mm}$ & $9.8 \mathrm{~mm}$ & $0.09 \%$ & $0.36 \%$ \\
\hline test no. 5 & $4.9 \mathrm{~mm}$ & $12.7 \mathrm{~mm}$ & $0.18 \%$ & $0.46 \%$ \\
\hline test no. 6 & $8.5 \mathrm{~mm}$ & $15.0 \mathrm{~mm}$ & $0.31 \%$ & $0.55 \%$ \\
\hline test no. 7 & $15.9 \mathrm{~mm}$ & $19.6 \mathrm{~mm}$ & $0.58 \%$ & $0.71 \%$ \\
\hline test no. 8 & $20.1 \mathrm{~mm}$ & $22.7 \mathrm{~mm}$ & $0.73 \%$ & $0.83 \%$ \\
\hline test no. 9 & $25.4 \mathrm{~mm}$ & - & $0.93 \%$ & - \\
\hline test no. 10 & $26.9 \mathrm{~mm}$ & - & $0.98 \%$ & - \\
\hline test no. 11 & $29.5 \mathrm{~mm}$ & - & $1.08 \%$ & - \\
\hline & & & &
\end{tabular}

\section{Damage description}

In this study three limit states are considered for the seismic response definition of the plasterboard partitions. In particular:

- $\quad$ OLS $\rightarrow$ Operational limit state (damage state 1 limit);

- $\quad$ DLS $\rightarrow$ Damage limit state (damage state 2 limit);

- $\quad$ LSLS $\rightarrow$ Life safety limit state (damage state 3 limit).

Operational limit state achievement implies the need of repairing the damaged element, in order to restore the original condition; damage limit state achievement, instead, implies that the component is damaged so that it must be partially removed and replaced; finally life safety limit state implies that the damage level is such that life safety is not ensured and the partition needs to be totally replaced.

After each test, damage is observed inspecting the specimen components. The recorded damage in each component is then correlated to one of the three limit states defined above. The level of damage required to reach a limit state is defined for each damage typology of each system component (i.e. plasterboards, studs, runners and screws). This damage is defined quantitatively, if possible; in the opposite case a qualitative definition of the level of damage is defined. Obviously, the damage state is the maximum between the different damage states recorded in each component.

Both bidirectional and unidirectional tests show a limited damage up to $1.08 \%$ drift, including:

- acrylic silicone, inserted in the separation between partition and wooden vertical support, detachment (Fig. 8a) in test no. 6 (partially) and in test no. 7 (complete);

- gypsum dust fall from test no. 7 with increasing intensity as the demand increases (Fig. 8b);

- cracking of the vertical joints between plasterboards in test no. 10 (Fig. 8c);

- crushing of the corners of the plasterboards in test no. 10 (Fig. 8d). 


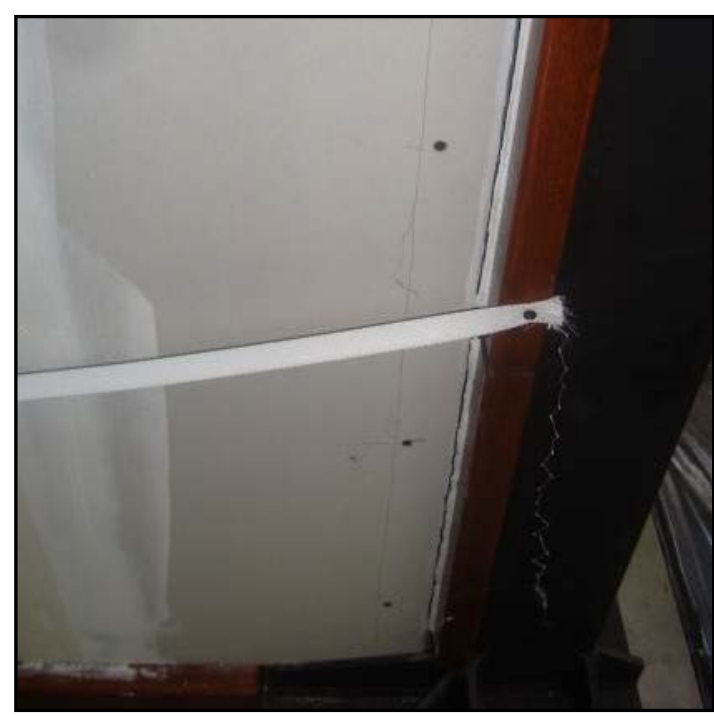

(a)

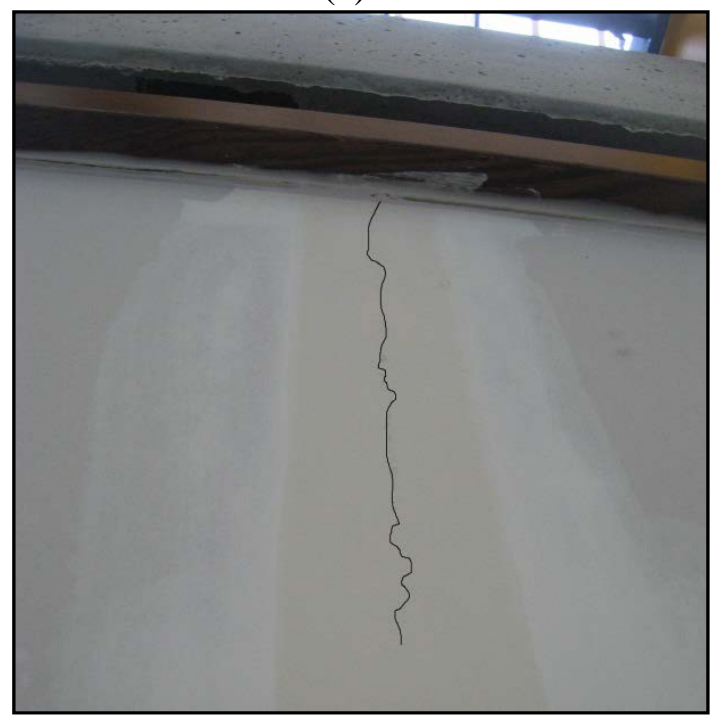

(c)

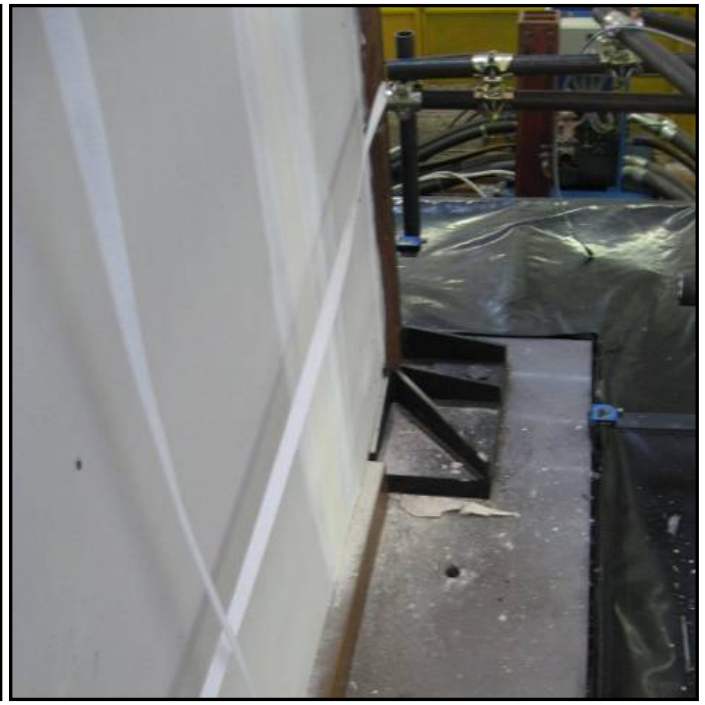

(b)

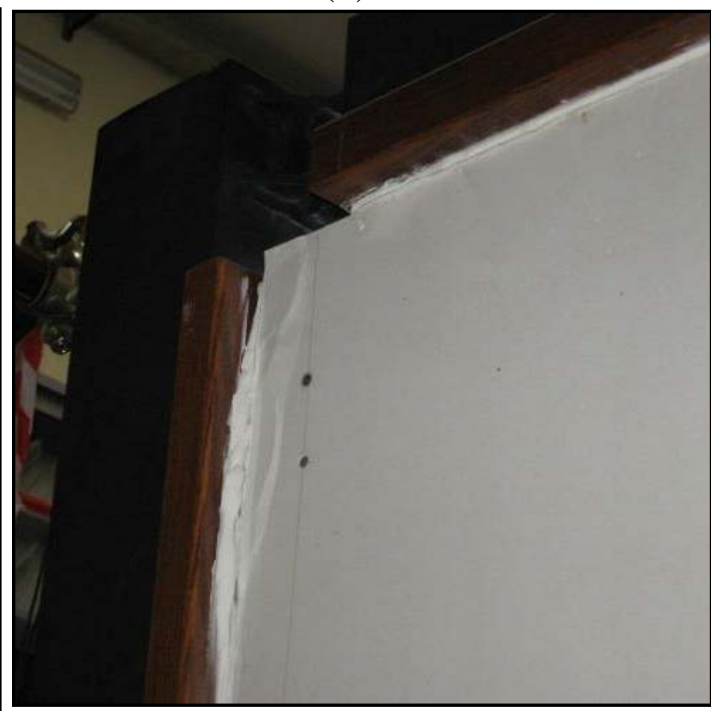

(d)

Fig. 8 Recorded damage after different shaking tests: (a) acrylic silicone detachment; (b) gypsum dust fall; (c) cracking of the vertical joints between plasterboards; (d) crushing of the corners of the plasterboards

The recorded damage yields that damage state 1 is attained for $0.58 \%$ drift level, due to the need of restoring the acrylic silicone, and damage state 2 is attained for $0.98 \%$ drift level, due to the need of replacing the plasterboards partially. The correlation between the damage states and the engineering demand parameters is based upon the assumption that the damage occurs at the maximum engineering demand parameter that the specimen experiences during a single test.

The tested partition systems exhibit a good behaviour under seismic actions. Particular attention, however, should be paid towards the definition of a large enough separation joint between partition and structure. This joint must be ensured both with the vertical structure (columns or partitions) and horizontal structure (slab). A smaller joint might compromise the system seismic performance.

Due to the particular construction technology, the partition behaves like a rigid block with three unrestrained degrees of freedom, i.e. horizontal translation and vertical translation in the partition plan and rotation around the orthogonal axis to the partition; when the structure exhibits displacements larger than the separation 
joint, the partition rigidly translates and rotates around a point at the base corner of the partition. For larger displacements the partition is stressed, stiffening the structure. This mechanism is widely supported by the analysis of tests video.

\section{Analytical results}

In order to analyse the test frame-partition interaction, the top acceleration, representative of the total inertia force, is plotted versus the relative displacement for different intensity levels (Fig. 9).

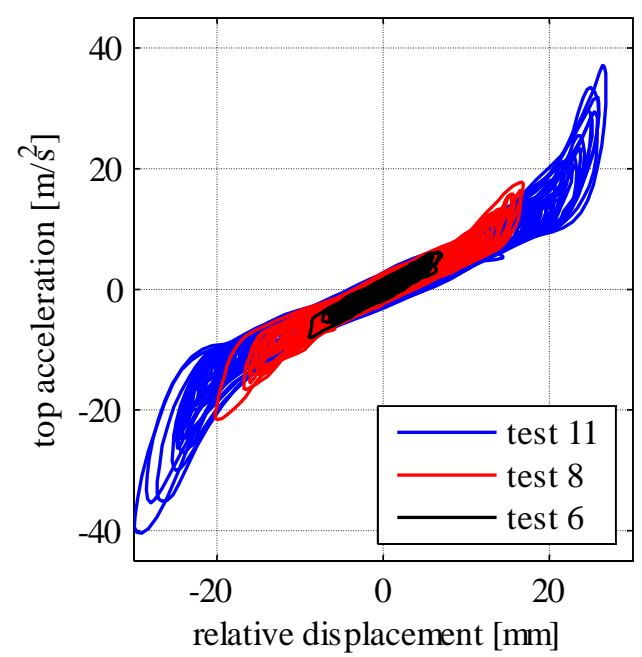

(a)

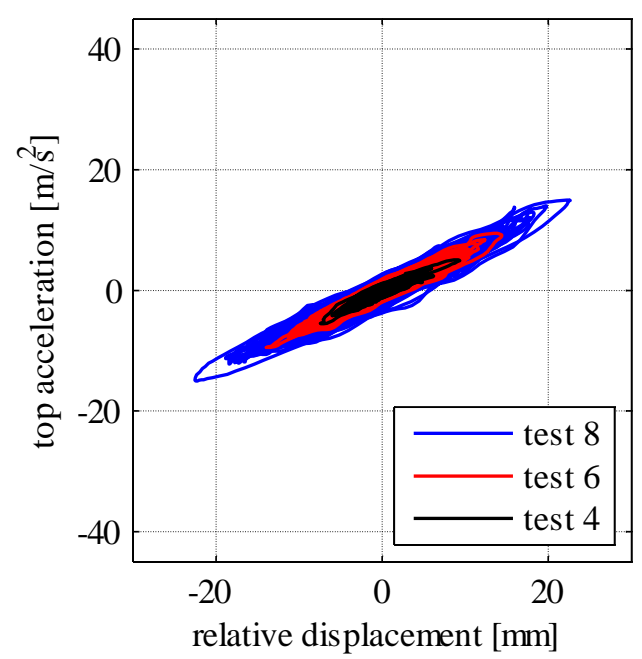

(b)

Fig. 9 Top acceleration vs relative displacement plot for the different seismic tests in (a) $X$ direction (b) Y direction

From the hysteretic curve in X direction (Fig. 9a) some comments can be stated:

- the trend of the hysteretic curve is linear until a $0.5 \%$ drift $(14 \mathrm{~mm})$ is reached, denoting no interaction between the partitions and the hosting structure; the slope of the initial linear envelope confirms the numerical model of the bare test frame: the linear trend slope, i.e. $(2 \pi f)^{2}$, is equal to 705 (rad/sec) $)^{2}$, corresponding to $4.23 \mathrm{~Hz}$ natural frequency;

- the contribution of the partitions is initially frictional, resulting in an increase of damping; for displacement close to twice the clearance between the partitions and the test frame, the energy dissipated increases due to the damage recorded within the partitions.

- the hysteretic behaviour of the partitions can be consistently assumed to be a relationship with initial gap; a significant increase of stiffness is recorded for large relative displacement.

The hysteretic curve in Y direction (Fig. 9b), i.e. partition out of plane direction, clearly shows that the partitions do not contribute to the lateral stiffness and strength in this direction, since the linear slope of the hysteresis loops corresponds to the bare test frame natural frequency.

\section{Frequency and damping evaluation}

Standard techniques for the evaluation of the natural frequency of the test setup allowed comparing the influence of the partitions on the natural frequency of the system (see Dynamic Identification Section). In the following paragraph the 
change in the natural frequency during the seismic tests is investigated in order to correlate the damages to the dynamic characteristics of the setup.

The transfer function, estimated as the ratio between the top and the base acceleration in the frequency domain, is applied with respect to the time histories recorded during the different seismic tests. This method allows following the change of the natural frequency during the tests, as shown in Fig. 10a.

The procedure proposed by Hashemi and Mosalam (2006), which allows evaluating the average values of stiffness $k$ and damping coefficient $b$ from the dynamic equilibrium, is also implemented. This method consists in evaluating the values of stiffness $k$ and damping coefficient $b$ of an equivalent single degree of freedom system that minimize the error in evaluating the dynamic equilibrium equation for each time instant. Based on the "average" stiffness, the natural frequency is evaluated and plotted in Fig. 10a for the different tests.

Assuming an exclusively viscous dissipation, the damping ratio $\xi$ is proportional to the ratio between the dissipated energy per cycle, $W_{D}$ (area enclosed within each hysteresis cycle), and the elastic energy $E$ (Chopra 2001) as follows:

$$
\xi=\frac{W_{D}}{4 \pi E}
$$

Each hysteresis cycle of a single test is isolated to calculate its area, i.e. the dissipated energy $W_{D}$, and the associated elastic energy $E$. This procedure provides as much damping values as the number of hysteresis cycles in each test. In Fig. 10b the median value of damping coefficient is plotted for each test.

The damping ratio $\xi$ is also evaluated from the procedure proposed by Hashemi e Mosalam (2006) using the theoretical expression:

$$
\xi=\frac{b}{2 \sqrt{k \cdot m}}
$$

where $k$ is the lateral stiffness mentioned above and $m$ is the mass of the equivalent single degree of freedom system. In Fig. 10b the damping ratio, evaluated according to the latter procedure, is compared to the equivalent viscous damping computed according to the energetic method.

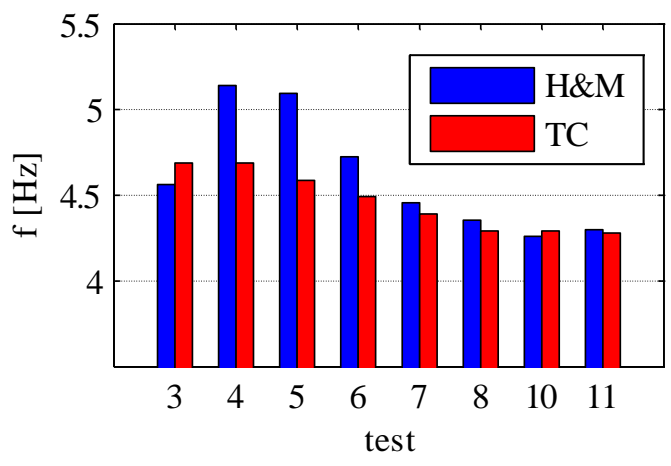

(a)

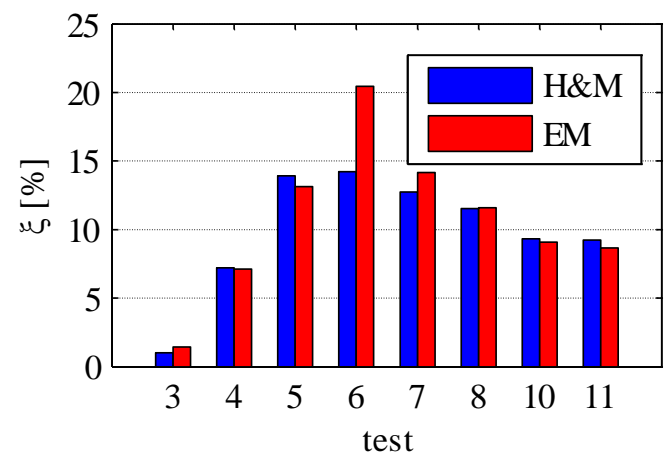

(b)

Fig. 10 (a) Natural frequency evaluation according to Hashemi and Mosalam (2006) (H\&M) procedure and transfer curve method (TC) for the different seismic tests; (b) damping ratio evaluation according to Hashemi and Mosalam (2006) (H\&M) procedure and the energetic method (EM) for the different seismic tests

The trend of both the natural frequency and the damping ratio confirms the recorded damage.

The presence of the acrylic silicone in the clearance between the test frame and the partition lightly contributes to the lateral stiffness in the first tests (small displacement demand), increasing the natural frequency. The decrease of the 
frequency in tests 6 and 7 denotes the failure of the acrylic silicone. Consequently the natural frequency tends to a lightly larger frequency than the bare test frame one. This is due to the fact that for large displacements, i.e. interstorey drifts larger than $0.5 \%$, the partitions collaborate with the test frame, stiffening the setup (Fig. 9a).

Similarly, from test 3 to test 6 an increase in the damping ratio and then a following decrease is exhibited, essentially due to the silicone progressive damaging. In test 6 a very high value of damping is recorded, mainly owed to two factors: the presence of the acrylic silicone which is a material characterized by high damping and the friction developed by the plasterboards that slide with respect to the top runner. Once the silicone is detached, the damping ratio decreases, since the damping due to the silicone vanishes.

\section{Base shear repartition}

Through the analysis of the hysteretic curves (Fig. 9) the base shear repartition between the partitions and the test frame is evaluated. The force adsorbed by the partitions is simply evaluated as the difference between the maximum inertia force and the force acting on the test frame; the latter force is calculated upon the natural frequency of the test frame and the attained displacement. The result is also validated using the strain gauge placed at the column base of the test frame.

In Fig. 11 the base shear distribution between partitions and test frames in every test is shown. It can be seen that the contribution of the partitions is initially negligible. Partitions start collaborating after test 7, when the acrylic silicone is detached. The quantity absorbed by partitions passes from a value of approximately $20 \%$ (test 6 ) to $50 \%$ of the total base shear (tests $10-11$ ).

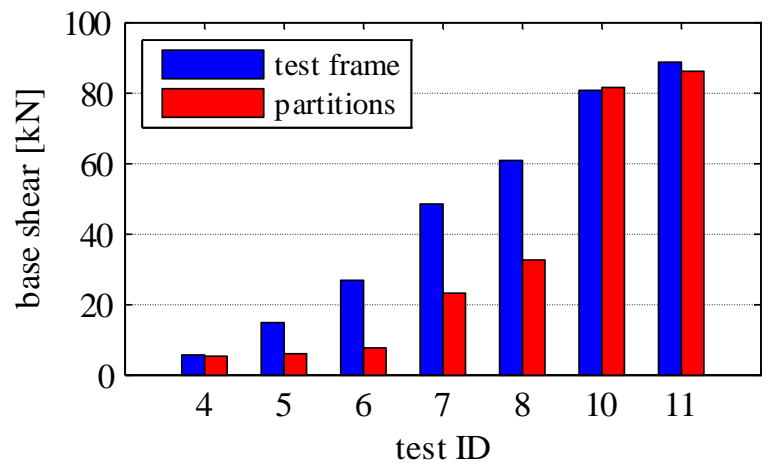

Fig. 11 Base shear repartition between test frame and partition systems for the different seismic tests

\section{Evaluation of the frequency of the component}

In order to evaluate the natural frequency in the out of plane direction, the transfer curve method is applied considering the base acceleration and the partition out of plane acceleration recorded by accelerogram no. 103763 (Fig. 12). The method is applied for the eight bidirectional tests, in which the partition is subjected to acceleration in the out of plane direction.

The transfer function in Fig. 12 yields two peaks: one with lower frequency, denoting the natural frequency in $\mathrm{Y}$ direction of the test frame that is constant for the different tests; the latter is related to the natural frequency of the nonstructural component in the out of plane direction. It should be noted that the frequency of the component decreases from a value of $16.8 \mathrm{~Hz}$ for test 1 to $11.5 \mathrm{~Hz}$ for test 8, being representative of the damage progression in the partition systems. 
The results confirm that the frequencies of the partitions are much larger than the typical structural fundamental frequencies. Hence, the ratio between the period of the nonstructural component $\left(\mathrm{T}_{\mathrm{a}}\right)$ and the period of the building $\left(\mathrm{T}_{1}\right)$, considered in Eurocode 8 (CEN 2004b) for the evaluation of the seismic demand on the component, could be accordingly assumed equal to zero.

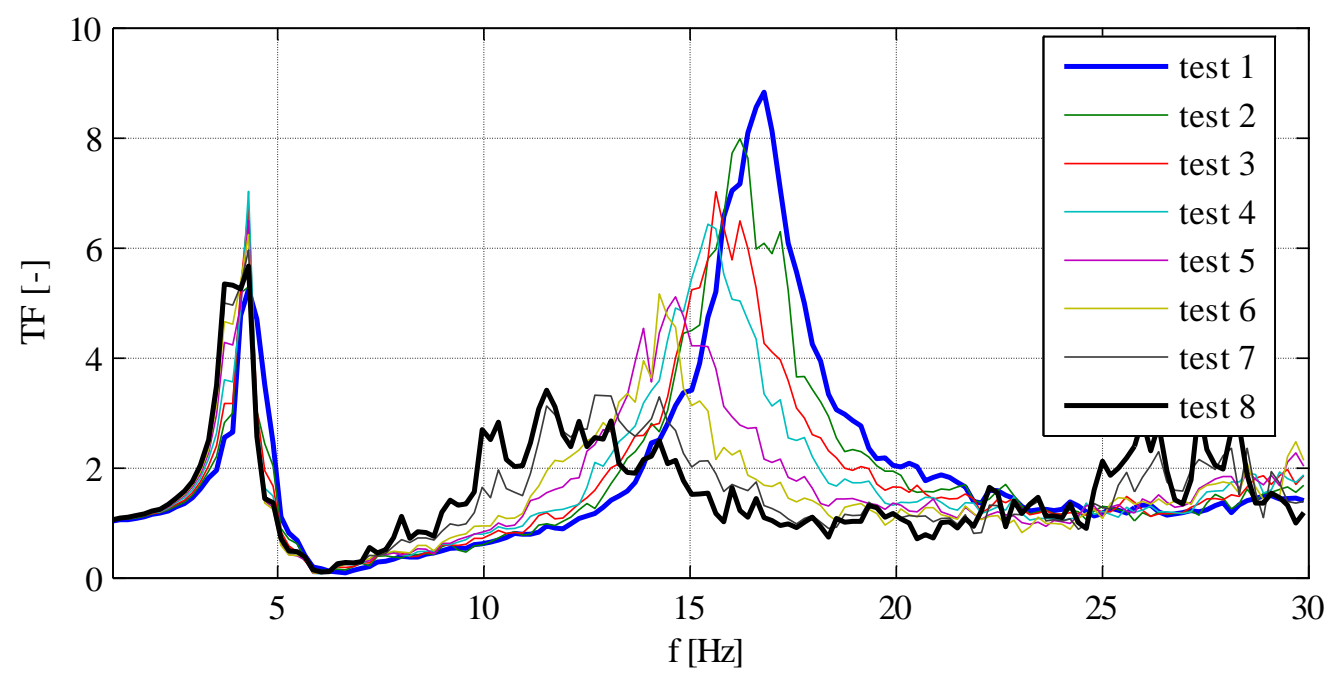

Fig. 12 Transfer function from the base to the partition centre in the out of plane direction for the bidirectional tests

\section{Analytical modelling: post-test dynamic analyses}

A numerical model of the test setup, i.e. the test frame and the partitions, is defined and subjected to the recorded base acceleration time-histories through OpenSees program (McKenna 2001). The test frame is modelled as a single degree of freedom system with a $4.33 \mathrm{t}$ equivalent mass and a lateral stiffness evaluated upon the outcomes of the dynamic identification procedures above mentioned.

The tested partitions are included into the model through the insertion of two translational springs in parallel:

- a brittle-elastic translational spring with stiffness equal to $k_{\text {sil }}$ that represents the contribution of the acrylic silicone to the lateral behaviour; based on the recorded damage, the contribution of the spring vanishes once a displacement larger than $10 \mathrm{~mm}$ is attained;

- an elastic with gap translational spring, defined upon the parameters $\delta_{G A P}$ and $k_{p a r}$, that represent the width of the gap and the contribution of the partition system to the stiffness once the silicone fails, respectively.

The unknown parameters of the model are:

- the gap dimension $\delta_{\mathrm{GAP}}$;

- the stiffness of the acrylic silicone $\mathrm{k}_{\text {sil }}$;

- the stiffness of the partition system $\mathrm{k}_{\mathrm{par}}$;

- the damping ratio $\xi_{\mathrm{i}}$, assumed to be different for each test.

The parameters of the model are set (Table 5) in order to minimize the difference between experimental and numerical results in terms of both maximum displacement/acceleration and dissipated energy. 
Table 5 Gap dimension, stiffness of the acrylic silicone spring and of the partition system adopted in the model

\begin{tabular}{ccc}
\hline$\delta_{\mathrm{GAP}}[\mathrm{mm}]$ & $\mathrm{k}_{\text {sil }}[\mathrm{kN} / \mathrm{m}]$ & $\mathrm{k}_{\mathrm{par}}[\mathrm{kN} / \mathrm{m}]$ \\
\hline 21.5 & 1260 & 14000 \\
\hline
\end{tabular}

The damping ratios necessary for the experimental-numerical matching for the different tests confirm the outcomes of the procedures summarized in Fig. 10b, passing form a value of $\xi=30 \%$ in test 6 to $\xi=5.5 \%$ in test 11 .

The results of the analyses (blue line) for tests $6(\xi=30 \%)$ and $11(\xi=5.5 \%)$ are compared in Fig. 13 and Fig. 14 with the experimental outcomes (red line) in terms of hysteresis loops and displacement time histories.

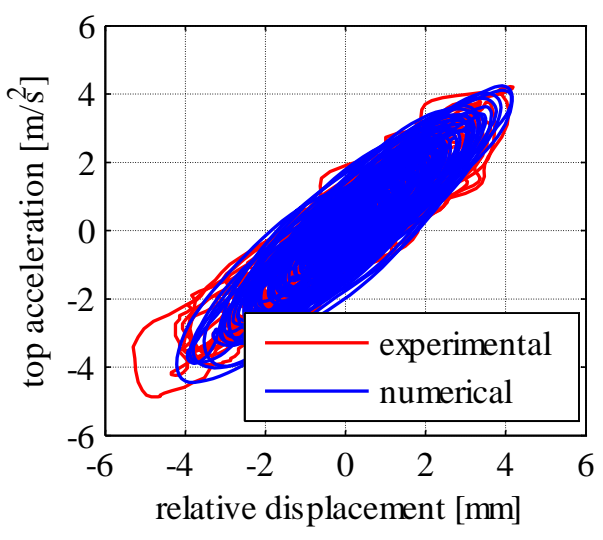

(a)

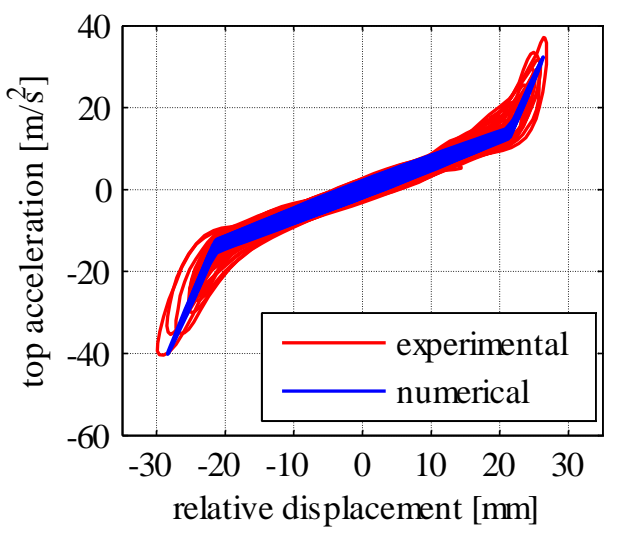

(b)

Fig. 13 Comparison between experimental and numerical hysteresis loop: (a) test 6; (b) test 11

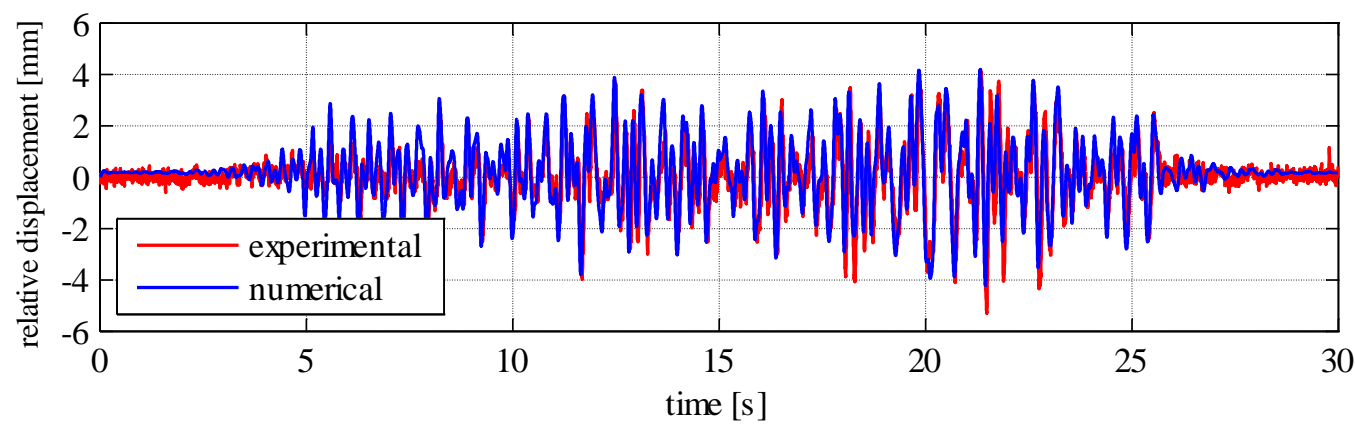

(a)

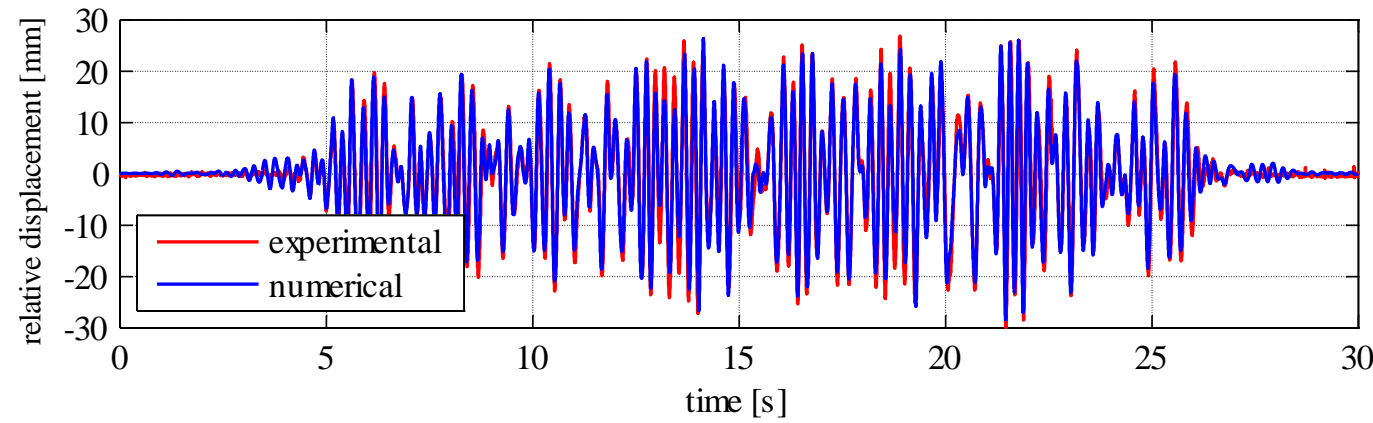

(b)

Fig. 14 Comparison between experimental and numerical time histories: (a) test 6; (b) test 11

The hysteretic curve comparison shows the good matching in terms of dissipated energy both for test 6 , in which the silicone exhibits significant damage yielding a large damping ratio, and for test 11, in which the silicone is failed and the 
partitions collaborate for large displacement. The comparison between displacement time histories shows the excellent matching between experimental and numerical results.

\section{Conclusions}

In order to investigate the seismic behaviour of plasterboard internal partitions produced by Siniat, shaking table tests are carried out by the earthquake simulator system available at the laboratory of the Department of Structures for Engineering and Architecture at the University of Naples Federico II.

A steel test frame is properly designed in order to simulate the seismic effects at a generic building storey. The tests are performed shaking the table simultaneously in both horizontal directions. To investigate a wide range of interstorey drift demand and seismic damage, the shakes are performed scaling the accelerograms at eleven different intensity levels.

Relative displacements are evaluated using laser sensors records. Values up to $1.1 \%$ drift are recorded, representative of a moderate earthquake intensity level. The tested partition systems exhibit a good seismic behaviour: a minor damage state is attained for $0.58 \%$ drift level, while a moderate damage state is attained for $0.98 \%$ drift level.

Standard methods for the dynamic identification of the test setup, both bare and infilled, are used in order to evaluate the influence of the plasterboard partitions on the steel test frame. The change in the natural frequency and the damping ratio during the different seismic tests is correlated to the recorded damages.

Finally, a numerical model of the test setup, i.e. the test frame and the partitions, is defined and subjected to the recorded base acceleration time-histories through the OpenSees program. The test frame is modelled as a single degree of freedom system. The hysteretic curve comparison shows a good matching in terms of dissipated energy, while the comparison of displacement time histories shows the excellent matching between experimental and numerical results.

It should be underlined that the above presented conclusions and results are related and limited to the tested innovative partition typology; the use of acrylic silicone, as well as the non-connection of the boards to the guides along the perimeter, substantially influences the overall behavior of the panel.

\section{Acknowledgements}

This research study has been funded both by Italian Department of Civil Protection in the frame of the national project DPC - ReLUIS 2010-2013 and by Siniat that also provided the partition systems for the testing program.

The advice provided by Antimo Fiorillo, structural engineer, in the definition of the test frame is gratefully acknowledged.

\section{References}

Adham SA, Avanessian V, Hart GC, Anderson RW, Elminger J, Gregory J (1990) Shear wall resistance of lightgage steel stud wall systems. Earthq Spectra 6:1-14

Anderson RW (1981) Investigation of the seismic resistance of interior building partitions. Agbabian Associates, El Segubehaviourndo, California, USA

Bertero RD, Bertero VV (2002) Performance-based seismic engineering: the need for a reliable conceptual comprehensive approach. Earth Eng Struct Dyn 31:627-652. doi: 10.1002/eqe.146 CEN (2005a) Eurocode 3: design of steel structures - Part 1-1: General rules and rules for buildings. EN 1993-1-1. Brussels, Belgium 
CEN (2004a) Eurocode 3: design of steel structures - Part 1-3: Supplementary rules for coldformed members and sheeting. EN 1993-1-3. Brussels, Belgium

CEN (2005b) Eurocode 3: design of steel structures - Part 1-8: design of joints. EN 1993-1-8. Brussels, Belgium

CEN (2004b) Eurocode 8: design of structures for earthquake resistance - Part 1: general rules, seismic actions and rules for buildings. EN 1998-1, Brussels, Belgium

Chopra AK (2001) Dynamics of Structures: Theory and Applications to Earthquake Engineering (2nd edition). Prentice-Hall:Upper Saddle River, NJ, USA

Computers and Structures, Inc (2012) SAP 2000: Linear and Nonlinear Static and Dynamic Analysis of Three Dimensional Structures, Berkeley, California, USA

De Stefano M, D'Ambrisi A, Tanganelli M, La Brusco A, Vignoli A, Borghini A, Del Monte E, Ortolani B, Sassu M, Andreini M, De Falco A (2012) Seismic risk analysis of public hospitals in Tuscany Region - Italy. Proceedings of 15th World Conference on Earthquake Engineering, Lisboa - Portugal, 24-28 September 2012

Earthquake Engineering Research Institute (EERI) (1984) Nonstructural Issues of Seismic Design and Construction, Publication 84-04, Berkeley, CA, USA

Filiatrault A, Mosqueda G, Retamales R, Davies R, Tian Y, Fuchs J (2010) Experimental Seismic fragility of Steel Studded Gypsum Partition Walls and Fire Sprinkler Piping Subsystems. Structures Congress 2010 (ASCE). doi: 10.1061/41130(369)237

Fulop LA, Dubina D (2004a) Performance of wall-stud cold-formed shear panels under monotonic and cyclic loading, Part I: Experimental research. Thin Walled Struct 42:321-338. doi:10.1016/S0263-8231(03)00063-6

Fulop LA, Dubina D (2004b) Performance of wall-stud cold-formed shear panels under monotonic and cyclic loading, Part II: Numerical modelling and performance analysis. Thin Walled Struct, 42:339-349. doi:10.1016/S0263-8231(03)00064-8

Hancock J, Watson-Lamprey J, Abrahamson NA, Bommer JJ, Markatis A, McCoy E, Mendis R (2006) An improved method of matching response spectra of recorded earthquake ground motion using wavelets. J Earth Eng, Special Issue 10:67-89. doi: 10.1080/13632460609350629

Hashemi A, Mosalam K (2006) Shake-table experiment on reinforced concrete structure containing masonry infill wall. Earth Eng Struct Dyn 35:1827-1852. doi: 10.1002/eqe.612

International Code Council (ICC) (2000) International Building Code, 2000 Edition (IBC 2000), Falls Church, Virginia, USA

International Conference of Building Officials (ICBO) (2000) ICBO AC 156 Acceptance Criteria for the Seismic Qualification of Nonstructural Components. ICBO Evaluation Service, Inc., Whittier, California, USA

Kanvinde AM, Deierlein GG (2006) Analytical Models for the Seismic Performance of Gypsum Drywall Partitions. Earth Spectra 22:391-411. doi: 10.1193/1.2191927

Landolfo R, Fiorino L, Della Corte G (2006) Seismic behavior of sheathed cold-formed structures: physical tests. J Struct Eng 132:570-581. doi: 10.1061/(ASCE)0733-9445(2006)132:4(570

Lee TH, Kato M, Matsumiya T, Suita K, Nakashima M (2007) Seismic performance evaluation of non-structural components: Drywall partitions. Earth Eng Struct Dyn 36:367-382. doi: 10.1002/eqe.638

Maddaloni G., Ryu K.P., Reinhorn A.M (2011) Simulation of floor response spectra in shake table experiments. Earth Eng Struct Dyn 40:591-604, doi: 10.1002/eqe.1035

Magliulo G, Manfredi G (2011) Shaking table test for analysis of seismic performance of Lafarge plasterboard partitions. Report 2010078-02, Department of Structural Engineering, University of Naples Federico II, Italy

Magliulo G, Pentangelo V, Maddaloni G, Capozzi V, Petrone C, Lopez P, Talamonti R, Manfredi G (2012a) Shake table tests for seismic assessment of suspended continuous ceilings. Bull Earth Eng 10:1819-1832. doi: 10.1007/s10518-012-9383-6

Magliulo G, Petrone C, Capozzi V, Maddaloni G, Lopez P, Talamonti R, Manfredi G (2012b) Shake table tests on infill plasterboard partitions. Open Constr Build Technol J 6 (Suppl 1M10):155-163. doi: 10.2174/1874836801206010155

McCormick J, Matsuoka Y, Pan P, Nakashima M (2008) Evaluation of non-structural partition walls and suspended ceiling systems through a shake table study. Structures Congress 2008 (ASCE):1-10. doi: 10.1061/41016(314)223.

McKenna F, Fenves GL. OpenSees Manual. Pacific Earthquake Engineering Research Center, 2001, http://opensees.berkeley.edu. Accessed 07 February 2013

Mosqueda G, Retamales R, Filiatrault A, Reinhorn A (2009) Non-structural components under full-scale floor motions. Struct Des Tall Spec Build 18:387-404. doi: 10.1002/tal.441

Paulay T, Priestley MJN (1992) Seismic design of reinforced concrete and masonry buildings. John Wiley \& sons, New York, USA 
Restrepo JI, Bersofsky AM (2011) Performance characteristics of light gage steel stud partition walls. Thin Walled Struct 49:317-324. doi:10.1016/j.tws.2010.10.001

Restrepo JI, Lang AF (2011) Study of loading protocols in light-gauge stud partition walls. Earth Spectra 27:1169-1185. doi: 10.1193/1.3651608

Retamales R, Mosqueda G, Filiatrault A, Reinhorn A (2011) Testing Protocol for Experimental Seismic Qualification of Distributed Nonstructural Systems. Earth Spectra 27:835-856. doi: 10.1193/1.3609868

Taghavi S, Miranda E (2003) Response assessment of nonstructural building elements, PEER report 2003/05, College of Engineering, University of California Berkeley, USA

Villaverde R (1997) Seismic design of secondary structures: state of art. J Struct Eng 123:10111019 